\title{
Tecnologia na iluminação cênica e a capacitação profissional: autonomia/ procedimentos automatizados
}

\author{
Technology in stage lighting design \\ and professional training: autonomy/ \\ automated procedures
}

Pedro Dultra Benevides ${ }^{1}$ 


\section{Resumo}

A tecnologia na iluminação cênica passou por sucessivas e constantes atualizações nos últimos anos, e um dos propósitos da indústria tem sido a fidelização de seus usuários. O presente texto apresenta uma reflexão sobre as influências desse contexto na capacitação dos profissionais. Reflito se a tecnologia pode condicionar a automatização dos procedimentos destinados à referida atividade artística. Para tanto, reúno fatos referentes à implantação dos sistemas de controle digital no Brasil; e, em seguida, exponho alguns procedimentos utilizados por artistas e técnicos envolvidos na iluminação. Por fim, especulo se mais influências promovidas pela tecnologia podem trazer consequências relevantes para o desenvolvimento de projetos de luz no teatro.

Palavras-chaves: Tecnologia; Iluminação cênica; capacitação profissional; autonomia; procedimentos automatizados

\section{Abstract}

In the last years scenic lighting technology has passed through several updates and one of the industry purposes has been the adherence of its users. This text presents a reflection on the influences of this context in the preparation of scenic lighting designers. I reflect on whether technology can condition the automation of artistic activity procedures. With this goal, I collect facts regarding the implementation of digital control systems in Brazil; and then, I expose some procedures used by artists and technicians involved in lighting design. Finally, I speculate if more influences promoted by technology may have relevant consequences for the development of scenic lighting design.

Keywords: Technology; stage lighting design; qualification; autonomy; automated procedures 
O presente artigo surgiu a partir da reflexão sobre a atividade do iluminador cênico e das influências promovidas pela constante atualização das consoles (mesas de luz) na sua atividade. O recorte temporal observado abrange os últimos vinte anos, períodos de migração e ampla implantação do sistema digital para controle de luz no mercado brasileiro. A partir deste recorte, pretende-se discutir questões pertinentes à autonomia do processo criativo dos profissionais. Para tanto, conceitos relativos à arte e à técnica, componentes inseparáveis da prática da iluminação cênica, estão presentes neste estudo.

Nota-se que os três tópicos escolhidos para a reflexão proposta - arte, técnica e autonomia no processo de trabalho - não são novidades no campo da prática teatral.

Entre os conceitos desenvolvidos por teóricos, um que se destaca é o de "aura" (ou seja, os elementos únicos de uma obra de arte original), formulado por Walter Benjamin (2017) no ensaio "A obra de arte na era de sua reprodutibilidade técnica", publicado em 1936. Esse ensaio é ainda hoje uma das principais referências para a reflexão de quaisquer atividades artísticas que aplicam procedimentos relacionados ao uso de ferramentas na produção artística.

As metodologias de trabalho empregadas na iluminação, aqui chamadas de técnicas, durante as duas últimas décadas adequaram-se às atualizações da tecnologia. Entre elas, a virtualidade, ou seja, os dados digitais ganharam destaque, sobretudo porque otimizaram os processos de trabalho nas condições de hardware e de software. Logo, aqueles que atuavam como técnicos e iluminadores atualizaram-se no uso dos recursos.

Durante a minha formação, experiência acumulada como técnico, iluminador e docente na graduação, vivenciei a transformação tecnológica a qual me refiro e, dentre as circunstâncias observadas, uma sempre chamou a minha atenção. Percebi que inúmeros profissionais, principalmente os iniciantes aprendizes, encantam-se com os recursos oferecidos pelos fabricantes de equipamentos de iluminação a cada lançamento.

Estes dispositivos passam por atualizações a partir de alguns fatores ${ }^{2}$, dentre esses, destaco a compatibilidade de integração entre plataformas de distintos fabricantes e as sugestões/demandas dos profissionais de referência internacional.

Nesse contexto composto por diversos interesses, observei que, além das vantagens proporcionadas pelas notáveis novidades, muitos usuários podem ficar expostos a certos riscos. Recorro a Mumford (1986, p. 13) para apresentar essa situação: "Numa atitude de submissão e auto abnegação, as pessoas começam a adorar a máquina e seus peritos". Tal adoração não seria um problema se ela não alavancasse mais desdobramentos.

Constatei que uma contradição se estabelece. A recorrente atualização do sistema de iluminação deveria servir para aperfeiçoar os processos de trabalho, e isso viria a colaborar com a árdua atividade dos profissionais envolvidos com a iluminação: criação, montagem, programação e operação. No entanto é possivel notar que a tecnologia pode induzir os usuários na automatização de procedimentos, tor-

\footnotetext{
2 Existe um fator que é a obsolescência programada. Neste caso a indústria prevê a substituição de um produto mesmo antes do seu lançamento, logo, ao encurtar o seu ciclo de vida, ela promove a aceleração do consumo.
} 
nando-os dependentes, ou pouco autônomos frente a suas demandas. Para além da capacitação profissional, foi possível observar que muitos usuários descartavam e ou ignoravam ferramentas, bem como procedimentos antes usuais e eficientes, sobretudo nas etapas de programação das consoles.

Quanto ao entendimento de autonomia, tomo emprestado o estudo de Eirado e Passos que se amparam na Teoria de Autonomia proposta por F. Varela:

Consideremos mais detidamente o sentido que Varela dá à noção de autonomia. Palavra composta de "auto", que quer dizer o próprio, o si-mesmo, e de "nomos", que quer dizer lei ou norma, autonomia seria, então, dar-se a si mesmo suas próprias regras, e se oporia a heteronomia, que indicaria o estado daquele, ou daquilo, que é regrado, determinado por outro". (Eirado; Passos, 2004, p. 78).

É justamente sobre o exercício da autonomia para a criação artística que pretendo refletir. Questiono se o período de instrumentalização, no uso da máquina ${ }^{3}$, condiciona os usuários ou não impede que eles se mantenham independentes no sentido de decidirem sobre os procedimentos mais adequados às suas necessidades. Adentro mais ao assunto quando reflito sobre as seguintes considerações de Mumford (1986, p. 68):

Para falar em termos biológicos, a relação do homem com a máquina deve ser simbiótica e não parasitária: e isto significa que ele deve estar pronto a dissolver essa parceria, ou mesmo renunciar, temporariamente, aos seus benefícios práticos, assim que eles ameacem a sua autonomia ou o seu desenvolvimento ulterior.

Sem dúvida, quando instrumentalizados, os profissionais se tornam especializados, assim, deveriam decidir pelas estratégias de trabalho mais adequadas a cada situação e ou demanda estética.

É objetivo deste trabalho, ainda, verificar se o aprendizado de novos recursos, oferecidos pelas consoles, podem condicionar procedimentos, tornando os usuários reféns de metodologias de trabalho. Nesta condição, eles passariam a reproduzir mecanicamente estratégias engessadas para executar projetos que, na maioria das vezes, têm fins artísticos, quando não, destinados ao entretenimento.

Encontro indícios para propor a reflexão trazida a partir de um fato rotineiramente observado: muitos profissionais que atuam no campo da iluminação cênica abusam da aplicação dos recursos oferecidos por hardwares e softwares. Tal condição não chamaria a minha atenção se os assim conhecidos "efeitos" estivessem em sintonia com a cena, seja ela musical ou teatral. Acredito que a praticidade, proporcionada pela tecnologia, favorece a automatização dos procedimentos desses profissionais. Desta maneira, eles acabam deixando de lado um aspecto importante do projeto: a construção de uma identidade visual singular para cada obra, ou seja, sua "aura".

Para refletir sobre as questões expostas, serão utilizados exemplos de dois con-

\footnotetext{
3 Entendida aqui como a integração entre hardware e software.
} 
textos nos quais o iluminador exerce a sua atividade: o show musical e a peça de teatro. Ambos foram contemplados com os mesmos recursos tecnológicos ao longo dos últimos anos.

Antes de prosseguir, destaco que não pretendo caminhar na contramão da tecnologia ou rejeitá-la. Meu interesse maior é ampliar o horizonte investigativo na área da iluminação alinhando-me à ideia, senso comum entre os artistas, de que o fazer artístico demanda autonomia do realizador.

Quanto à bibliografia na área da iluminação que trata diretamente do tema aqui abordado, observo que não encontrei referências diretas. No entanto alguns estudos relacionados a pedagogias no ensino de iluminação tangenciam o assunto, como o artigo de Ronaldo Fernando Costa (2008). Por fim, lembro que ainda é limitada a produção bibliográfica no campo da iluminação cênica, assim concordam Eduardo Tudella (2017) e Roberto Gil Camargo (2000), por exemplo.

\section{Adaptação e migração de sistemas de controle}

Há aproximadamente vinte anos no Brasil, a tecnologia de controle de iluminação cênica migrou do sistema analógico para o sistema digital. A transição foi lenta porque as empresas fabricantes competiam pelo domínio da tecnologia 4 e, por outro lado, quando adquiridos pelos teatros ou pelas empresas de locação, esses equipamentos chegavam com altos custos, impostos e demandavam adequação ou reforma dos espaços cênicos.

A indústria nacional já produzia consoles e dimmer box analógicos. Mas frente à nova realidade, ela buscou parcerias com desenvolvedores da área de eletrônica, para assim produzirem os equipamentos digitais e se manterem competitivas no mercado.

No novo sistema, o dimmer box digital passou a oferecer maior sensibilidade às transições de cenas de luz, elevando exponencialmente a precisão das variações de intensidades entre $0 \%$ e 100\%. Fabricantes nacionais, como Ci Tronics, Ditel (posteriormente Telem), Star, dentre outras, ganharam mercado e aprimoraram a qualidade dos seus equipamentos. Atualmente, esses fabricantes distribuem seus produtos por todo o território nacional. Já outros fabricantes não conseguiram se manter, passando por processos de fusão com outros ou foram à falência.

Quando se tem em vista o mercado brasileiro dos últimos vinte anos, deve-se ter em mente duas situações. A primeira é a proporção continental do país, com diversos perfis de clientes e respectivas exigências. A segunda decorre de alguma forma da primeira: formação especializada e restrições financeiras.

O que os profissionais consideram como qualidade de condições de trabalho, no tocante à técnica, dá lugar a precariedade em regiões menos favorecidas, por exemplo. A carência de formação, inclusive no manejo da eletricidade, associada à limitação de recurso, à falta de conhecimento sobre os modelos de sistemas e dos aparelhos de emissão de luz, são exemplos observados por quaisquer artistas e téc-

4 O consenso no uso do Protocolo DMX 512 viabilizou a aquisição de equipamentos. Com esse sistema foi possível integrar periféricos de distintos fabricantes 
nicos, residentes próximos de capitais ${ }^{5}$, em suas turnês.

Tais casos são recorrentes em cidades de pequeno porte. Até muito pouco tempo, os povoados longínquos demoravam de acessar a oferta de equipamentos mais modernos e não contavam com quaisquer suportes. Seu consumo atendia à demanda local, geralmente com produções que dispunham de reduzido orçamento. Quanto ao tipo e modelo desses equipamentos, restava aos interessados adquirir o que encontrassem. Geralmente esses refletores eram de baixa qualidade ${ }^{6}$, e mesas de luz nacionais, porém extremamente simples ${ }^{7}$. Em alguns casos, não raros, é comum encontrar grupos de teatro que reutilizaram equipamentos descartados por produções de maior porte ou por espaços culturais.

Por outro lado, alguns centros urbanos, sobretudo aqueles com maior poder aquisitivo, contam com cursos de formação na área de eletricidade básica e com teatros que recebem produções de maior porte. Este último fator favorece a capacitação profissional. Além disso, algumas poucas cidades contam com o suporte de fabricantes, representantes e ou de distribuidores de equipamentos. Esse conjunto de fatores contribui para o crescimento da demanda, seja ela por parte da indústria, seja por parte dos usuários, ávidos pela constante atualização tecnológica.

Entretanto, um fator serviu de meio para "democratizar" a informação. A rede internacional de computadores igualou a demanda entre centros urbanos e localidades mais afastadas. Todos passaram a desejar "a novidade", sobretudo em canais de exibição de show. Contudo o aporte para aquisição dos objetos de desejo ainda destoa.

\section{Relação entre tecnologia e usuário}

Independente da condição geográfica dos usuários, o sistema digital surgiu com inúmeras vantagens. Dentre elas, destaca-se o fato de que o tempo de trabalho dos profissionais foi otimizado. Nesta tecnologia, as cenas passaram a ser gravadas numa memória interna das consoles. Além disso, as atualizações de cenas (ou edições) passaram a ser feitas a qualquer momento, em poucos segundos durante os ensaios de pré-estreia, ou em temporadas. A ferramenta também favoreceu os testes e sucessivas simulações nas condições reais em que a obra seria levada ao público.

Antes, com o sistema analógico, os testes também aconteciam durante os ensaios. No entanto a qualidade na execução do evento estava tanto na condição do equipamento quanto, ou mais importante, no desempenho do operador de luz. Esse profissional deveria conhecer a obra iluminada, a console, e executar as mudanças de luz conforme as indicações do iluminador, organizadas em um roteiro de operação.

Atualmente, durante a preparação de uma obra, os ensaios ainda são uma etapa imprescindível, pois é nesse momento em que todos os elementos envolvidos se encontram. Nas peças de teatro, sobretudo na véspera da estreia, os operadores en-

\footnotetext{
5 É usual encontrar profissionais capacitados próximos a cidades de maior porte. Ainda assim, regiões mais afastadas dos grandes centros urbanos também contam com profissionais experientes.

${ }^{6}$ Baixa qualidade tanto na condição de eficiência luminosa (sem lâmpadas adequadas e sem lentes) quanto sem dispositivos de segurança.

7 Faders não ofereciam precisão nas trocas de luz, e possuíam botões (bumps) frágeis, que logo demandariam manutenção.
} 
saiam junto com o elenco; simultaneamente, o iluminador orienta o operador, corrige e aprimora seu projeto. Já nos shows de música a condição de trabalho não é tão diferente, porém muitos iluminadores são os programadores e operadores durante as turnês ${ }^{8}$.

A tecnologia não minimizou a importância dos operadores, pelo contrário, os novos suportes modificaram sua nomenclatura. Os fabricantes de consoles passaram a utilizar a expressão "programadores", conforme empregado na área da informática.

Nos últimos quinze anos, os avanços digitais foram ainda mais significativos. A eletrônica (hardware) e a informática (software) praticamente não se dissociam. Os arquivos puderam ser extraídos das mesas de luz e transportados em disquetes e posteriormente em pen drive, e então, quando necessário, descarregados numa mesa de luz. Antes, eles ficavam presos à console; defeitos inesperados poderiam comprometer toda a produção, não são poucos os casos em que isso aconteceu.

A integração entre a ciência da computação e os periféricos de um sistema de iluminação contribuiu para todos os profissionais envolvidos nas linguagens artísticas mencionadas. A título de exemplo, as produções tiveram redução nos seus custos.

A reprodução dos projetos sempre dependeu de viabilidade, por isso questões relacionadas a custos ganham relevância e até mesmo determinam a durabilidade de uma obra. Quanto às produções, dois aspectos podem ser observados. O primeiro é o custo de locação dos equipamentos. Por exemplo: em vez de transportar as mesas de luz de um lugar para outro, as produções passaram a locar este periférico na véspera do evento. O segundo aspecto diz respeito à mão de obra empregada. No sistema analógico os equipamentos eram muito pesados, geralmente fabricados com ferro e alumínio. As lâmpadas incandescentes, muito potentes, o que demandava cabos resistentes, pesados, que teriam que ser distribuídos entre cabine, central de energia e palco para integrar mesa, dimmer box e refletores respectivamente. Atualmente, alguns modelos de refletores contam com baterias internas de alta duração e recebem os comandos da mesa de luz via rádio, o que dispensa cabeamento de sinal.

Esses exemplos evidenciam que os projetos ficaram mais econômicos no tocante à contratação de mão de obra. Com a tecnologia disponível, em poucas horas, uma reduzida equipe técnica monta o sistema de iluminação e o operador transfere para a mesa todas as "cenas de luz" . De uma forma geral, toda a equipe técnica conta hoje com melhores condições de trabalho, como, por exemplo: equipamentos compactos, mais leves, menor consumo de energia etc.

Todo o conjunto de melhorias técnicas aqui descrito refletiu no trabalho do iluminador, refiro-me ao seu desenho, ou seja, à reprodutibilidade da obra de uma apresentação para outra.

\footnotetext{
8 Ainda que a profissão de iluminador seja a mesma, algumas características variam entre os profissionais que se dedicam às duas linguagens (cênica e musical). Para manter o foco na discussão do objeto do estudo, evito entrar em detalhes sobre os perfis dos iluminadores. Aponto brevemente que existem diferenças e que alguns profissionais transitam bem na criação cênica e musical. Já em outros casos, não raros, os iluminadores de shows de música não têm relação com o campo das artes cênicas.
}

9 Expressão recorrente no âmbito dos profissionais em iluminação cênica. 


\section{Suportes para a reprodução da identidade de um projeto}

Dado esse brevíssimo panorama, já é possível adentrar no primeiro tópico pretendido a partir de um caro conceito: a condição da "aura" na reprodução de um projeto de iluminação.

Peças de teatro e show de música são obras artísticas produzidas para exibição ao vivo ${ }^{10}$. As decisões visuais geralmente são concebidas e preparadas para as estreias; em seguida, são reproduzidas durante as inúmeras apresentações. Ajustes para adequação entre os conceitos concebidos e a visualidade ${ }^{11}$ são recorrentes após as estreias. Esta situação me permite estabelecer um paralelo entre a condição da "aura" num projeto de iluminação em analogia às considerações de Benjamin $(2017$, p. 56):

[...] mesmo na reprodução mais perfeita uma coisa se perde: o aqui e agora da obra de arte - sua existência única, e somente nela, que está realizada a história à qual a obra de arte esteve submetida no decorrer de sua duração.

O autor, no seu ensaio, não refletiu sobre a condição da iluminação cênica. Seus comentários referem-se à produção cinematográfica, e em algumas passagens do seu ensaio, à preparação da iluminação nos estúdios de gravação, para realização das tomadas - registro audiovisual - das cenas. A título de exemplificação, nas etapas posteriores da gravação, ou seja, na pós-produção, os registros visuais e sonoros passam por tratamento antes da montagem. Quando finalizado, o filme torna-se reproduzível sem variação, no que tange à relação de conceitos artísticos e de visualidade. Benjamin comenta sobre as perdas durante a preparação de um filme, como a perda da "aura" num estúdio durante a gravação.

Diferente da condição técnica da obra cinematográfica, na linguagem da iluminação cênica, o Desenho de Luz é montado a cada temporada, quando não, semanalmente para as apresentações. Sua condição cênica traz uma particularidade, o Desenho do iluminador não é o objeto principal contemplado pelo espectador. Ele serve à cena, seja ao trabalho do ator ou dos músicos. Sobre um palco, a luz combinada em composições constrói climas e imprime emoção em imagens visíveis, compostas por volumes, dos corpos ou cenográficos, e em conjunto com a sonoridade. Todos os elementos se encontram e são expostos ao espectador.

A exata reprodução de efeitos de luz garante excelência à produção. Casos como esse são constatados com artistas consagrados, rotineiramente de repercussão internacional, como, por exemplo, as bandas U2, Rolling Stones etc.; no teatro, por tradição, não é diferente.

Já na linguagem cinematográfica, o filme é a obra em si. Muito se perdeu no "aqui e agora" do processo iniciado nos estúdios de gravação e até mesmo durante a edição. Diferente do que Benjamin afirma sobre a era da reprodutibilidade técnica no cinema, percebo que a "aura" não se atrofia no projeto de iluminação cênica, quando ele é devidamente adaptado.

\footnotetext{
10 O registro das obras também é feito, assim como o streaming e o download de pacote de dados obtidos pela internet. No entanto tratarei apenas de apresentações ao vivo na presença do espectador.

11 Refiro-me à visualidade, como construção de imagem cênica, conforme Tudella (2017).
} 
No tocante aos suportes técnicos mais uma diferença se acentua entre as linguagens. A tecnologia digital viabilizou a reprodutibilidade técnica do Desenho de Luz ao proporcionar maior precisão na execução das sequências das cenas de luz entre os atos, ou a cada música. Hoje, por exemplo, as mesas de luz usam as plataformas desenvolvidas pela indústria da informática, como, por exemplo: Linux, Windows ou Apple.

A integração com essas plataformas permitiu que as cenas de luz fossem gravadas previamente à montagem do equipamento. A principal vantagem para a produção, como um todo, é que o referido recurso reduziu o tempo de trabalho em campo (arquitetura teatral ou estruturas ao ar livre), inclusive para os ajustes de um dia para outro. O ganho de tempo nos procedimentos técnicos encurtou o processo de integração dos testes de luz com os artistas da cena.

Quanto a etapa de criação, os softwares de visualização de luz se desenvolveram enquanto simuladores. Com eles o iluminador simula com grande margem de precisão o seu projeto, ainda no seu escritório ou no conforto do seu home office. Existem também outros softwares sem visualização ${ }^{12}$, que permitem a gravação, e estão disponíveis para o download na internet.

Para a etapa de operação, a integração com a informática ofereceu aos operadores diversos recursos de acionamento das memórias gravadas. Destaco aqui os tempos de entrada, saída, permanência e delay, assim como ferramentas que permitem ao operador parar e até acelerar a transição da luz dos tempos gravados ${ }^{13}$.

Antes de prosseguir, enfatizo que existem aspectos que merecem exposição quando se tem em vista os recursos de operação de luz em apresentação musicais e cênicas. A título de exemplo, em shows, ainda que tocada ao vivo por humanos, a música obedece a contagens de tempo, logo permite gravação prévia para execução de efeitos. No teatro, as cenas pré-gravadas contam com um aspecto inerente a essa arte: sua efemeridade. Refiro-me às condições de cena realizadas ao vivo.

Mesmo com inúmeros ensaios, o artista está suscetível a variações a cada apresentação no teatro, seja na relação com demais atores ou mesmo de humor. Neste caso, as gravações das cenas de luz, com tempos pré-estabelecidos, podem comprometer a cena. Por isso alguns iluminadores preferem os tradicionais métodos de operação, como o crossfader, por exemplo. Com esse suporte é possível acompanhar o deslocamento do intérprete em cena ou seguir seus silêncios nos intervalos de fala. Com vista nessa realidade, os fabricantes mantêm nas mesas de luz as opções tradicionais de operação.

\section{O fator humano}

Antes, no sistema analógico, e conforme apresentado o caso, após toda parte técnica montada (refletores, cabos e afinação), os iluminadores tinham que dedicar

\footnotetext{
12 Particularmente, aplico uma metodologia empregada por iluminadores que tive oportunidade de trabalhar. Tive contato com esse meio de trabalho com o iluminador brasileiro Jorginho de Carvalho. A gravação em home office sem visualização 3D tem seus limites, sua aplicação é mais apropriada para instrumentos com lâmpada, ou seja, quando se controla apenas intensidade. Aparelhos com mais de um parâmetro, como os leds ou robotizados, demandam minimamente as condições de visualização em software para gravação antecipada.

13 Refiro-me às funções Hold, BACK do sistema EOS da fabricante ETC
} 
muitas horas à organização da mesa de luz, assim como treinar para realizar da forma mais precisa possível os complexos ou simples efeitos. A ideia de tempo, na troca de cenas, dependia da contagem humana, logo, intuitiva, relativamente imprecisa.

Uma característica notável do momento em que só havia o sistema analógico é que alguns técnicos e iluminadores se destacavam como operadores de luz. $\mathrm{O}$ profissional deveria dominar o equipamento e, além disso, senão mais importante, desenvolver sua percepção artística para contracenar, executando com precisão as trocas de luz entre as cenas.

Podemos acrescentar agora, para diferenciar a arte da técnica, que a arte é a parte da técnica que sofre a maior marca da personalidade humana; a técnica é aquela manifestação da arte da qual uma grande parte da personalidade humana foi excluída para favorecer o processo mecânico. (Mumford, 1986, p. 24).

A condição de um operador tem outra natureza no teatro, sua ação não deve ser mecanizada. Silêncios e movimentações cênicas demandam a devida atenção de quem opera a luz. Considerar a condição da "aura" num projeto de iluminação implicava na premissa da escolha do operador.

Essa condição do profissional não mudou. A operação de luz, com a cena realizada por intérpretes é um fator inerente ao teatro, por exemplo. Por isso os suportes da tecnologia, qualquer que seja ela, não minimizaram a importância dos operadores na sua responsabilidade em conhecer intimamente a obra.

[...] cheguei a uma compreensão referente à participação dos profissionais que orbitam ao redor do espetáculo, e que pude aplicar em todas as minhas experiências posteriores. Percebi que os técnicos não só servem à cena nos bastidores, eles de fato contracenam durante toda a peça com os atores. Contracenar aqui se caracteriza como uma comunhão na realização do espetáculo. (Dultra, 2012, p. 26).

Esses técnicos foram contemplados com outros recursos da tecnologia. As atuais consoles foram projetadas também para atender a eventos em que o improviso é uma condição. Nelas um programador pode preparar uma apresentação em poucos minutos $^{14}$. Com o toque dos dedos numa tela touch screen, esse técnico, na condição de programador, seleciona aparelhos robotizados, grava diversas posições (ou seja, ângulos de incidência de luz em qualquer ponto do palco), seleciona GOBOS e cores isoladamente, por exemplo ${ }^{15}$. Em seguida, ele escolhe num banco de dados as opções de efeitos mais adequadas a sua demanda.

Por analogia, assim como um cozinheiro que separa antes os ingredientes num "mise en place" e em seguida cozinha inúmeros pratos, o programador, durante o show, já na condição de operador, dispara inúmeros efeitos combinando suas seleções pré-programadas, ou palletes como são conhecidos. A cada música, fazendo uso das mesmas paletas de cor, posições e gobos, ele imprime ritmo e emoção a uma apresentação.

\footnotetext{
14 O exemplo dado é uma realidade rotineira para shows de música, quando bandas realizam apresentações em festivais de pequeno porte e não dispõem de condição para solicitar equipamentos que atendam ao projeto original concebido pelo iluminador.

15 Além de variações de intensidade esses instrumentos têm parâmetros, como troca de cor e movimento, por exemplo.
} 
É bem possível que os emocionados espectadores não tenham noção de que aquele show de luzes foi preparado em poucos minutos e o improviso, associado à experiência e sensibilidade do profissional, garantiu o espetáculo.

Pelo exposto, nota-se a transformação das condições de trabalho nas artes cênicas, inclusive é possível supor que em breve o teatro será ainda mais impactado. Em curto prazo, não é possível falar apenas em benefícios para os iluminadores e para os programadores/operadores nesta atividade artística.

\section{Autonomia x automatização}

Ao se considerar a relação entre aspectos humanos (os profissionais) e técnicos (enquanto ferramentas) envolvidos na iluminação cênica, pode-se afirmar que a máquina desponta com mais protagonismo a cada ano. Não é possível negar que as condições de trabalho melhoraram, contudo algumas consequências imprevistas também podem ser evidenciadas. Aqui destaco o condicionamento dos profissionais no uso automatizado das consoles. Aspectos relacionados à formação dos profissionais também serão brevemente comentados no presente tópico.

Inúmeras funcionalidades presentes nas mesas de luz podem comprometer a condição da autonomia e de tomadas de decisões dos usuários. Mumford (1986, p. 16) reflete sobre o condicionamento do usuário no uso da máquina: "O grande problema do nosso tempo é restaurar o equilíbrio e a integridade do homem moderno: dar-lhe a capacidade de comandar as máquinas que criou, em vez de se tornar o seu cúmplice impotente e vítima passiva".

Essa cumplicidade impotente pode ser evidenciada a partir da implantação do sistema digital. Como exemplo, observo as funcionalidades e consequências do uso da console inglesa "Pearl 2000", fabricada pela Avolites e lançada no ano de 1999. O lançamento foi um sucesso no Brasil, o alcance internacional fez com que a fabricante atualizasse o software e o hardware da Pearl até o ano de 2008.

Popularizada entre os técnicos, a função shapes foi absorvida, festejada pelos profissionais e aprimorada pelas empresas concorrentes. Essa função nada mais é do que um algoritmo de geração de efeitos. Com ela, deixou de ser necessário programar completamente todos os parâmetros para os aparelhos robotizados, por exemplo. Após a escolha de um shape específico, no banco de dados da mesa, o programador pode editar parâmetros de velocidade para: movimento, para "fade in" / "fade out" e para troca de cor, por exemplo. Então, um mesmo shape pode ser usado para gerar efeitos visuais distintos, acompanhando com distintos climas, na condição de imagem, as músicas num show.

Desde o seu lançamento, os consumidores/usuários usaram e abusaram do que aqui nomeio "novidades visuais". Por que trago a expressão "novidades visuais"? Frutos de uma indústria que induz ao consumo, muitas vezes iluminadores renomados são convidados pelos empresários para assinar um show de nível internacional. Além da divulgação do artista, a indústria promove o lançamento de novos equipamentos. $O$ registro desses eventos atinge os mais longínquos territórios com a internet. Artistas (das mais variadas categorias) assistem a esses espetáculos e passam a desejar 
aqueles efeitos em suas apresentações. Por sua vez, o iluminador e ou o programador são influenciados e até mesmo induzidos a reproduzi-los.

Atualmente, metade dos ganhos em eficiência técnica são anulados pelo hábito de modernizar anualmente o estilo. Os diretores de publicidade e os designers industriais empregam um extraordinário talento para fazer com que os modelos pareçam ter sofrido uma grande modificação, quando na realidade isso não aconteceu. (Mumford, 1986, p. 73).

Se vista com olhar crítico a iluminação de muitos shows de música, é possível constatar um descompasso entre cena e luz, em inúmeros casos. Nota-se, com isso, que o cuidado com a criação de uma identidade visual foi deixada de lado, e que apenas os efeitos foram "celebrados". Muitos programadores investem no uso dos shapes apenas para estimular ininterruptamente o espectador. Desconsideram, inclusive, que a constante exposição ao efeito pode provocar relativa "monotonia" e até dispersão.

Até a popularização da função shape, o iluminador era tido como uma "divindade", alguém que domina conhecimentos técnicos e tem ideias que beiram a genialidade. Longe de ser apenas um dom, a atividade do iluminador é carregada de complexidade. Quanto à plasticidade, por exemplo, a tendência desde o séc. XX para a montagem de peças teatrais é a criação de situações únicas para cada montagem. Situações pautadas numa dramaturgia e principalmente na interpretação que o diretor faz dela, ou seja, a marca do seu discurso. Por vezes, com foco no trabalho do ator, essa marca também pode ser percebida na imagem construída, por consequência, na relação: ator, cenografia, iluminação etc.; ou, conforme Tudella (2017), para a criação de uma visualidade.

A contradição, hoje, é que muitos usuários, sobretudo iniciantes, deixam a cargo do algoritmo inserido nas mesas aquilo que deveria ser o seu constante exercício: construir imagens aderentes à cena.

Exemplos como esse último permitem constatar que a formação dos usuários dos sistemas de iluminação muitas vezes é lacônica. Ávidos pelo domínio da máquina, muitos profissionais se restringiram ao domínio das questões de ordem técnica. Por outro lado, muitos técnicos e iluminadores se apropriam dos recursos oferecidos pelas tecnologias e os adéquam às suas demandas. Assim reconstroem sentido, sobretudo para ajustar ao perfil e estilo musical dos artistas que eles iluminam.

As lacunas na formação, por vezes resultam de processos de aprendizagem informal. Logo, se não orientados, esses aprendizes podem não dar a atenção ou mesmo ignorar assuntos pertinentes ao trabalho com iluminação.

No Brasil, ainda, o meio para o interessado aprender iluminação é acompanhando iluminadores profissionais. Esse processo expõe o aprendiz à prática com as ferramentas, e no diálogo constante com os profissionais eles compreendem a necessidade de conhecimento referente ao processo cognitivo humano conforme relata Luciane (2014, p. 17):

[...] o exercício profissional intuitivo de Beto Bruel, de quem eu era assistente na época, confrontado ao conhecimento científico da formação em design. O que eu ensinava aos alunos em formação [...] foi, durante algum tempo 
ainda, uma combinação de conceitos e linguagens do design com o uso feito da luz nos trabalhos com iluminação aos quais assistia. Essa realidade só se modificou algum tempo mais tarde, com o aprimoramento de minha própria atividade como iluminadora e professora.

De alguma maneira, assim como Luciani (2014), me envolvi em diversas produções na condição de assistente e posso afirmar que não somos casos isolados.

Particularmente, sempre estive atento às metodologias de trabalho dos profissionais que conheci. Dentre todas as etapas do processo que envolve o Desenho de lluminação, a programação da luz era o momento mais esperado, porque ali era possível se visualizar o que foi projetado e montado.

Nas oportunidades de trabalho em que o iluminador também era o operador, observei que muitos deixavam de lado sua autonomia na construção das cenas e investiam em praticidade na gravação da mesa de luz. É importante ressaltar que essa atitude não determinava a qualidade do resultado final.

Ainda que não existam apenas condições ideais a todo instante, ou seja, quando os operadores/programadores encontram variantes de ordem técnica, eles se veem obrigados a fazer ajustes de última hora. Adaptação é a expressão mais aderente a situações como essa. Adaptar um projeto de iluminação não significa fazer o possível e de qualquer maneira. Mas sim equalizar os princípios artísticos do projeto, às variações de ordem técnica, como distintos modelos de equipamentos, arquitetura e infraestrutura, por exemplo.

Então o que leva um teatro a adquirir o equipamento mais adequado à sua condição? Condição essa composta de arquitetura e perfil de atividade artística.

Os equipamentos de iluminação são desenvolvidos com vista na sua aplicação final. Quanto às mesas, seus hardwares variam, não só entre os fabricantes. Ao se olhar para uma mesa, é possível distinguir se ela foi construída para show ou para teatro ${ }^{16}$. Já os softwares das interfaces de teatro e show de música são muito semelhantes, afinal de contas eles controlam luzes.

Com vistas nessas questões, retomo um aspecto que compõe a realidade de muitos teatros: a desinformação. Não limitada aos usuários, profissionais de outras áreas (administrativas/financeiras) são envolvidos nas decisões referentes à aquisição de equipamentos nos teatros e nos centros de cultura. Contextos como esse ressaltam a importância da disseminação do conhecimento no campo da lluminação Cênica para instrumentalizar com conhecimentos elementares os profissionais envolvidos no setor cultural. Exemplos que atestam tal afirmação podem ser observados em diversos teatros onde as deliberações de setores financeiros/administrativos dificultam a atividade dos artistas. É comum encontrar nos teatros consoles que não atendem aos eventos rotineiros daqueles espaços. Inclusive, equipamentos mal escolhidos inviabilizam seu uso em algumas condições.

No teatro, por exemplo, quando silêncios preenchem as cenas, um refletor não deveria emitir nenhum ruído. Já para espaços abertos, pequenos ruídos não interferem na cena, principalmente se for musical.

\footnotetext{
${ }^{16}$ Eventos musicais demandam teclas de disparos, enquanto que mesas de teatro demandam faders. De maneira geral, ambos os modelos são compostos por teclas de disparo e faders, porém em quantidade eles variam para as distintas aplicações. As mesas de teatro também utilizam o par de crossfader, isso porque o pensamento da luz geralmente é encadeado por sequência de composições.
} 


\section{A título de fechamento: aplicação ao teatro}

Ao se observar as condições até aqui expostas de ordem técnica, questiono: até que ponto a atividade de criação está, ou pode ser pautada nos recursos disponibilizados pelos equipamentos? Ou mesmo, um(a) iluminador(a) de teatro, por exemplo, corre o risco de adotar os procedimentos mecânicos, conforme aqueles já comentados anteriormente e aplicados em alguns eventos musicais?

Refiro-me à relação com a máquina, no uso de suas funções para iluminar genericamente as cenas com novidades visuais, situação essa oposta à condição de autonomia criativa para investigação de visualidades que, por sua vez, conferem autenticidade à obra.

Com vistas na influência da indústria sobre os usuários, é possível supor que num futuro próximo as mesas de luz tenham um banco de dados que ofereça aos "artistas" estilos estéticos (para peça realista, épica etc.). A partir desse recurso, caberia, portanto, ao "iluminador", selecionar e ajustar parâmetros, como dia, noite, verão, inverno etc., a marcação do elenco e posicionamento da cenografia de uma peça.

O desenvolvimento de algoritmos poderá, inclusive, fragilizar a importância da participação de iluminadores. Suponho que será possível, em breve, que grandes produções ofereçam projetos de luz de peças já consagradas. Assim, não será necessário requisitar a participação de um(a) iluminador(a) para uma remontagem. Qualquer produção ou direção interessado(a) terá a concepção desenvolvida por um(a) iluminador(a) consagrado(a) para uma memorável montagem. Para tanto, deverá fazer apenas o download do projeto e adequar à sua montagem.

\section{Referências}

ABOUT Avolites. Avolites.[2018?] Disponível em: http://support.avolites.com/company/avolites-history. Acesso em: 20 out. 2019.

ALBUQUERQUE, Rodney. Devmedia. 2016. Disponível em: https://www.devmedia. com.br/nocoes-basicas-de-algoritmo/26405. Acesso em: 20 out. 2019.

BENJAMIN, Walter. A obra de arte na era de sua reprodutibilidade técnica. Porto Alegre: L\&PM, 2017.

CAMARGO, Roberto Gill. Função Estética da Luz. Sorocaba: TCM Comunicação, 2000.

COSTA, Ronaldo Fernando. Iluminação Cênica e uma construção do espetáculo: uma abordagem pedagógica. Anais ABRACE, Volume 9, n 1, 2008, p. 1-6.

DULTRA, Pedro. Em cena: o lluminador. Rio de Janeiro: Musica e Tecnologia, 2012.

EIRADO, A.; PASSOS, E. A noção de autonomia e a dimensão do virtual. Psicol Estudo, 9 (1), 2004, p. 77-85. 
LUCIANI, Nadia Moroz. Iluminação cênica: uma experiência de ensino fundamentada nos princípios do design. Florianópolis, 2014. Dissertação (Mestrado) - Centro de Artes, Universidade do Estado de Santa Catarina. Disponível em: http://www.tede. udesc.br/handle/tede/1190. Acesso em: 15 jan. 2020.

MUMFORD, Lewis. Arte \& Técnica. Porto, Portugal: Martins Fontes, 1986.

TUDELLA, Eduardo. A luz na gênese do espetáculo. Salvador: Edufba, 2017.

Recebido em: 30/10/2019

Aprovado em: 03/02/2019 